\title{
Neuroimaging manifestations of epidermal nevus syndrome
}

\author{
Andrea De Vito ${ }^{1}$, Ajay Taranath ${ }^{2}$, Hisham Dahmoush ${ }^{3}$, Shankar Srinivar Ganapathy ${ }^{4}$, Sniya Sudhakar ${ }^{5}$, \\ Kshitij Mankad ${ }^{5}$
}

${ }^{1}$ Department of Neuroradiology, H. S. Gerardo Monza, Monza, Italy; ${ }^{2}$ Department of Radiology, Women's and Children's Hospital, North Adelaide, South Australia, Australia; ${ }^{3}$ Department of Radiology, Lucile Packard Children's Hospital, Stanford University School of Medicine, Stanford, CA, USA; ${ }^{4}$ Department of Radiology, Akron Children's Hospital, Akron, OH, USA; ${ }^{5}$ Department of Radiology, Great Ormond Street Hospital, London, UK

Correspondence to: Kshitij Mankad, MD. Department of Radiology, Great Ormond Street Hospital, Great Ormond Street, London WC1N 3JH, UK. Email: drmankad@googlemail.com.

\begin{abstract}
Epidermal nevus syndrome (ENS) represents a diverse group of rare neurocutaneous diseases associated with the presence of characteristic epidermal nevi (EN) in the skin and extracutaneous manifestations in the eyes, skeletal, urogenital and central nervous systems. We present a case series of 7 children with ENS, with specific attention to the neuroradiological characteristics of this entity.
\end{abstract}

Keywords: Central nervous system diseases; hemimegalencephaly (HME); linear sebaceous nevus syndrome

Submitted May 05, 2020. Accepted for publication Aug 24, 2020.

doi: 10.21037/qims-20-634

View this article at: http://dx.doi.org/10.21037/qims-20-634

\section{Introduction}

Epidermal nevus syndrome (ENS) is a term used to represent a diverse group of neurocutaneous diseases in which one of the subtypes of epidermal nevi (EN) are found in association with extracutaneous abnormalities involving the eyes, nervous, skeletal, and urogenital systems (1). Most EN are present at birth and typically follow the lines of Blaschko (2). Blaschko's lines refer to the S-shaped or $\mathrm{V}$-shaped whorled, streaked, and linear patterns that are believed to represent the dorsoventral migratory pathways of the neuroectoderm during embryogenesis (2). The incidence of EN has been reported to range from 1 to 3 per 1,000 live births, without gender predominance $(2,3)$. Numerous phenotypes with different clinical appearances and histopathological features have been described (4), such as the nevus sebaceous syndrome (NS), nevus comedonicus syndrome (NC), phakomatosis pigmentokeratotica (PPK), proteus syndrome, and congenital hemidysplasia with ichthyosiform erythroderma and limb defects (CHILD) syndrome (5). In terms of CNS abnormalities however, hemimegalencephaly (HME) is the most striking finding, typically found on the side of the skin lesion, associated often with polymicrogyria $(4,6)$. Other neuroimaging findings can be grey matter heterotopia, atrophy with dystrophic calcification and hamartomas $(7,8)$. Cerebellar involvement has also been described. Vascular abnormalities are rare, including vessel dysplasia and infarction (9). The molecular basis of ENS spectrum is unclear. The syndrome has been observed sporadically in the relatives of affected patients. It has been hypothesized that it is a form of mosaicism of a lethal autosomal dominant gene $(5,10)$. Recent reports of somatic mosaicism in the pathogenesis of ENS have been reported, along with the identification of HRAS and KRAS mutations $(11,12)$.

\section{Case presentation}

\section{Case 1}

A 7-year-old girl presented with new-onset of generalized seizures and developmental delay in multiple domains. Physical examination revealed an epidermal nevus on the left trunk. Ophthalmological assessment showed bilateral optic nerve colobomata and corneal opacification. Brain MRI demonstrated two small lipomas on the dorsal surface of the cervicomedullary junction (Figure $1 A$ ). There was also moderate generalised cerebral atrophy (Figure $1 B$ ) with 

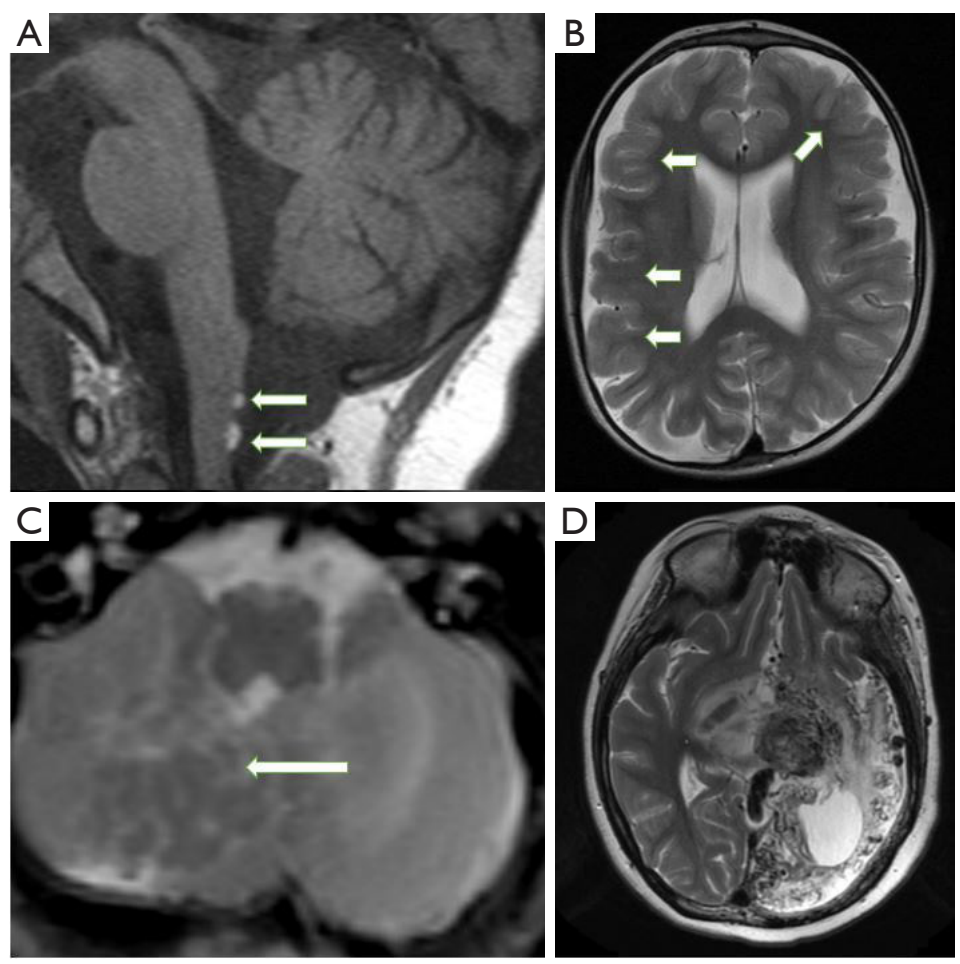

Figure 1 MRI scans showing cerebral and cerebellar abnormalities. (A) Sagittal T1-WI showing two dorsal cervico-medullary lipomas. (B) Axial T2-WI showing generalized brain atrophy with some areas of cortical dysplasia (arrows). (C) Axial T2-WI showing right cerebellar grey matter heterotopia (arrow). (D) Axial T2-WI showing left hemispheric proliferative arteriopathy.

mild prominence of the subarachnoid spaces overlying both hemispheres and inferior cerebellar vermian dysplasia.

\section{Case 2}

A female infant presenting with right-sided seizures at week 1 of life, with evidence of an epidermal nevus of the neck and right cheek noticed at 6 months of age. Right hemifacial hypertrophy, prominent right eye with associated exotropia and congenital nystagmus were noted on examination. Brain MRI at 1 month of age showed right cerebral HME with extensive areas of cortical dysplasia and associated neuronal migrational abnormality within the cerebellum, consistent with heterotopic grey matter (Figure 1C).

\section{Case 3}

A 3-day-old boy with right facial hypertrophy, right epidermal nevus, right ocular enlargement, nystagmus and developmental delay presented with medical refractory right-sided seizures. CT and MRI scan performed at day
9 of life showed an extensive right cerebral and cerebellar HME. He underwent functional hemispherectomy at the age of 12 months.

\section{Case 4}

A 7-year-old girl was diagnosed with a large left neck and cheek epidermal nevus. Left cerebral arterio-venous malformation was diagnosed when she presented with right sided weakness and refractory seizures. She underwent multiple embolizations. Historical images were not available but CT scan and MRI scan at age 18 showed a left-sided extensive proliferative arteriopathy with associated brain atrophy (Figure 1D).

\section{Case 5}

An 8-year-old boy presenting with vomiting and headache. He was noted to have a right facial nevus. Brain MRI revealed a large medulloblastoma in the posterior right cerebellar hemisphere which was resected in 2015 (Figure 2A). He had 

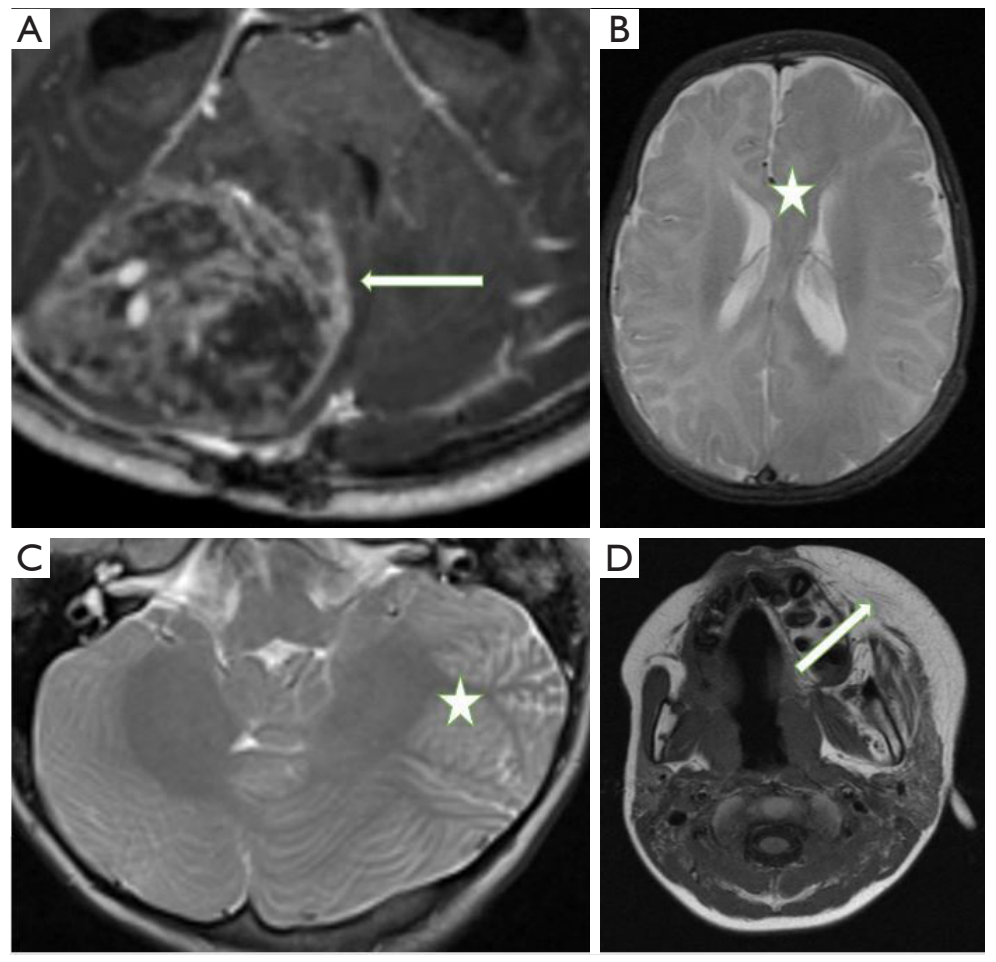

Figure 2 MRI scans showing supra- and infratentorial abnormalities. (A) Axial T1-WI after contrast administration showing a right cerebellar hemispheric medulloblastoma. (B) Axial T2-WI showing left HME involving the corpus callosum (star); (C) Axial T2-WI showing left cerebellar hemimegalencephaly (HME) with associated cortical dysplasia (star); (D) Axial T1-WI showing left facial lipomatous hypertrophy.

a large local recurrence 3 years later.

\section{Case 6}

An 8-year-old boy with left facial hypertrophy and ipsilateral neck and trunk nevus presented with new onset left-sided seizures and developmental delay. Brain MRI showed a left cerebral and cerebellar hemispheric (Figure 2B) HME with extensive cortical dysplasia within both structures (Figure 2C).

\section{Case 7}

A 15-month-old boy presenting with new-onset focal left frontal epilepsy and developmental delay. Physical examination showed a left facial nevus. Brain MRI revealed an extensive left cerebral HME (Figure 2D).

\section{Discussion}

ENS is not one disease, but rather a heterogeneous and diverse cluster of different disorders which have been categorized together (10). Several specific syndromes with overlapping features have been described, namely, the NS syndrome, Proteus syndrome, PPK (coexistence of nevus sebaceous with melanocytic nevi) and Keratinocytic ENS (10-14). These have been summarized in Table 1.

The cutaneous features of ENS depend on the predominant cell type involved histologically, the degree of cellular differentiation, the body site involved, and the age of the patient. EN typically follow several well recognized patterns of cutaneous mosaicism, typically "the lines of Blaschko" (2). Various methods of classifying EN have been proposed over the years. The concept that nevi may show differentiation towards various skin structures and glands, comprising of pilosebaceous, apocrine, eccrine glands and keratinocytes, has been the basis of most clinical classifications to date $(5,15)$. The two main subtypes are Nevus sebaceus (with excessive sebaceous glands components) and Keratinocytic EN (lesions without any adnexal components).

In terms of the genetic basis of ENS, the published evidence suggests that the clinical expression of ENS is based on genomic mosaicisms (16). The primary genes 
Table 1 Classification of epidermal nevus syndrome

\begin{tabular}{|c|c|c|c|}
\hline Syndrome & Type of epidermal nevus & Salient clinical features & Genetics \\
\hline Phakomatosis Pigmentokeratotica & Nevus Sebaceus & $\begin{array}{l}\text { Additional presence of nevus spilus papulosus, } \\
\text { arranged in a checkerboard pattern }\end{array}$ & HRAS \\
\hline Nevus Comedonicus syndrome & Nevus Comedonicus & Ipsilateral cataract and skeletal anomalies & FGFR2 \\
\hline Proteus syndrome & Keratinocytic Nevus & $\begin{array}{l}\text { Cerebriform connective tissue nevi of palms or } \\
\text { soles; asymmetric macrodactyly }\end{array}$ & AKT \\
\hline CHILD syndrome & CHILD Nevus & $\begin{array}{l}\text { Lateralized, inflammatory skin lesions; } \\
\text { ptychotropism; ipsilateral limb defects }\end{array}$ & NSDHL mutations \\
\hline
\end{tabular}

FGFR, fibroblast growth factor receptor; AKT, protein kinase B; NSDHL, NAD (P) dependent steroid dehydrogenase-like.

thought to be responsible for ENS are the ones involved in the Ras/MAPK signaling pathways; hence the term mosaic RASopathies is commonly used (11). The genes involved in the pathway include KRAS, HRAS, NRAS and FGFR1 $(11,17,18)$. FGFR2 and FGFR3 mutations have also been reported to be involved in some cases $(11,19)$.

Sebaceous Nevi are mostly located on the scalp or face, although they can be more widespread. They have a salmon to yellow color and a characteristic smooth waxy surface and can be complicated by eczematous reactions (14). Keratinocytic EN (KN) are another type of EN typically found on the trunk and extremities. They appear as linear or whorled skin-colored to pink or slightly hyperpigmented plaques that may be unilateral or bilateral.

Central nervous system involvement has been noted to be the most commonly described systemic association with ENS, presenting with a constellation of signs and symptoms ranging from headaches, epilepsy, focal motor deficits and developmental delay (20). Ophthalmological findings described include epibulbar lipodermoid, coloboma, corneal opacities and defects of the optic nerves, while associated skeletal abnormalities are craniofacial defects, frontal bossing, kyphoscoliosis, hip dislocation and limb deformities $(21,22)$.

Spanning the last 20 years, some cases of ENS have been published describing their neuroimaging manifestations, as summarized in Table 2. Our search strategy on PubMed, developed in consultation with a librarian with expertise in health research and systematic reviews, included terms related to ENS HME (in studies published from 1995). A broad approach was taken through the inclusion of all possible synonyms and abbreviations for the terms of interest, and controlled vocabulary/ subject headings (including MeSH, EmTree).

\section{HME}

HME is the most common structural brain abnormality encountered in the different subsets of ENS. As a corollary, ENS is the most common neurocutaneous disorder associated with HME (28). The distinctive triad of hemifacial EN, ipsilateral HME, and lipoma was first described by Gross and Uiberrak in 1955, who introduced the term "hemimegalencephaly." Pavone and colleagues also reported HME in 17 out of 60 patients with ENS, their study being a review of the literature and based on pathology or CT studies (28). Menascu et al. (25) described MRI abnormalities in 3 patients with ENS showing HME, polymicrogyria and cortical heterotopia while Pavlidis et al. (26) reported a boy with right 'total' HME, with increased volume of both cerebellar and cerebral right hemisphere.

In our series, HME was found in 4 patients out of 7 , 
Table 2 Literature review

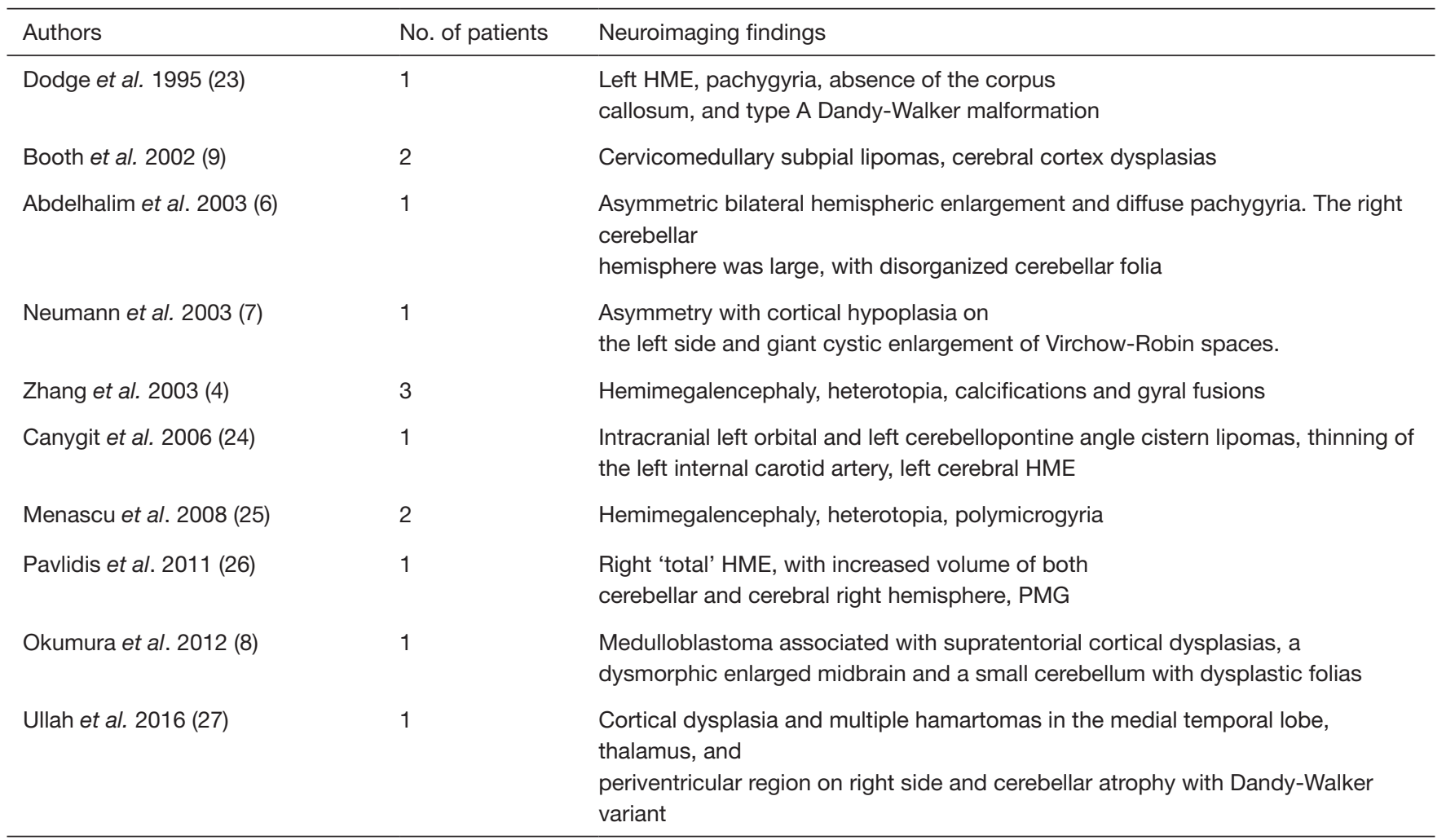

HME, hemimegalencephaly; PMG, polymicrogyria.

mostly right-sided. 2 of these patients showed both cerebral and cerebellar involvement. Furthermore, HME was always ipsilateral to the epidermal nevus.

\section{Cerebellar involvement}

Dodge et al. showed severe hypoplasia of the cerebellum with upward rotation of the vermis and a large retrocerebellar cyst in a 6-month old girl with infantile spasms (23). Also, Ullah et al. (27) reported cerebellar atrophy and cerebral cortical dysplasia in a 25-year-old girl. Abdelhalim et al. (6) reported an infant with ENS characterized by enlargement of both cerebral hemispheres, malformed basal ganglia, and unilateral enlargement of cerebellar hemisphere with disorganized folia.

Infratentorial anomalies were shown in 5 patients of our series, represented by HME, atrophy (unilateral and bilateral) and cerebellar heterotopia.

\section{Lipomas}

Intracranial and intraspinal lipomas represent rare manifestations of ENS; 2 patients from Booth et al. (9) showed the presence of subpial lipomas dorsal to the cervicomedullary junction, in association with very subtle dysplasias involving the cerebral cortex ipsilateral to the nevi. Left orbital and left cerebellopontine angle cistern lipomas were present in the series from Canyigit et al. (24).

We found 2 dorsal cervicomedullary lipomas in 1 patient, in association with cerebral and cerebellar atrophy.

\section{Neoplasms}

Bourdeaut et al. reported an oncogenic KRAS mutation in a patient with ENS associated with rhabdomyosarcoma (12) while Okumura et al. (8) showed a 51-day-old boy with neonatal medulloblastoma associated with cerebral and cerebellar cortical dysplasia. A right lateral medulloblastoma was present in 1 patient from our series, along with an ipsilateral nevus.

\section{Vascular abnormalities}

Juan et al. (29) revealed multiple sites of intra-thoracic and abdominal arterial stenoses and aneurysm formations 
in association with ENS in one patient, while Canyigit et al. (24) reported a 27-month-old boy with thinning of the left internal carotid artery (ICA) with occlusion at the T-junction.

We had one case with the presence of a large hemispheric arteriovenous malformation that was embolized on multiple occasions.

\section{Differential diagnosis}

ENS overlaps with HME spectrum of disorders, some entities within both these two groups being caused by similar mutations in the mTOR pathway. As such, HME with the co-existence of an epidermal nevus is very specific for ENS.

Further, within the neurocutaneous metameric disorders, Sturge-Weber syndrome (SWS), PHACES, MCAP (Megalencephaly-Capillary malformation), Parry-Romberg Syndrome (PRS) and encephalocraniocutaneous lipomatosis (ECCL) may all present as potential differentials, but associated CNS manifestations like a pial angioma (SWS) or characteristic segmental hemangiomas with posterior fossa malformations, ocular and cerebral arteries anomalies (PHACES), or hemifacial atrophy with both brain parenchyma anomalies (PRS), or presence of craniofacial lipomas with regional brain malformation (ECCL) (30) help differentiate these entities from ENS.

ENS is a rare spectrum of neurocutaneous disorders, all characterized by the presence of different types of EN with associated extracutaneous manifestations. CNS symptoms are common and ocular, skeletal and urogenital findings can be associated. Intracranial involvement is best evaluated with MR imaging and neuroimaging findings range widely, with the most common finding being HME. Rarer findings include intracranial/intraspinal lipomas, vascular anomalies and neoplasms.

\section{Acknowledgments}

Funding: None.

\section{Footnote}

Conflicts of Interest: All authors have completed the ICMJE uniform disclosure form (available at http://dx.doi. org/10.21037/qims-20-634). Dr. KM serves as an unpaid Associate Editor of Quantitative Imaging in Medicine and Surgery. The other authors have no conflicts of interest to declare.

Ethical Statement: Written informed consent was obtained from the patients for publication of this study and any accompanying images. A copy of the written consent is available for review by the Editor-in-Chief of this journal.

Open Access Statement: This is an Open Access article distributed in accordance with the Creative Commons Attribution-NonCommercial-NoDerivs 4.0 International License (CC BY-NC-ND 4.0), which permits the noncommercial replication and distribution of the article with the strict proviso that no changes or edits are made and the original work is properly cited (including links to both the formal publication through the relevant DOI and the license). See: https://creativecommons.org/licenses/by-nc-nd/4.0/.

\section{References}

1. Solomon LM, Fretzin DF, Dewald RL. The epidermal nevus syndrome. Arch Dermatol 1968;97:273-85.

2. Solomon LM, Esterly NB. Epidermal and other congenital organoid nevi. Curr Probl Pediatr 1975;6:1-56.

3. Alper J, Holmes LB, Mihm MC Jr. Birthmarks with serious medical significance: nevocullular nevi, sebaceous nevi, and multiple café au lait spots. J Pediatr 1979;95:696-700.

4. Zhang W, Simos PG, Ishibashi H, Wheless JW, Castillo EM, Breier JI, Baumgartner JE, Fitzgerald ME, Papanicolau AC. Neuroimaging features of epidermal nevus syndrome. AJNR Am J Neuroradiol 2003;24:1468-70.

5. Happle R, Rogers M. Epidermal nevi. Adv Dermatol 2002;18:175-201.

6. Abdelhalim AN, Moritani T, Richfield E, Ekholm SE, Westesson PL. Epidermal nevus syndrome: megalencephaly with bihemispheric and cerebellar involvement: imaging and neuropathologic correlation. J Comput Assist Tomogr 2003;27:534-7.

7. Neumann LM, Scheer I, Kunze J, Stöver B. Cerebral manifestations, hemihypertrophy and lymphoedema 
of one leg in a child with epidermal nevus syndrome (Schimmelpenning-Feuerstein-Mims). Pediatr Radiol 2003;33:637-40.

8. Okumura A, Lee T, Ikeno M, Shimojima K, Kajino $\mathrm{K}$, Inoue $\mathrm{Y}$, Yoshikawa N, Suganuma H, Suzuki M, Hisata K, Shoji H, Takanashi J, Barkovich AJ, Shimizu T, Yamamoto T, Hayashi M. A severe form of epidermal nevus syndrome associated with brainstem and cerebellar malformations and neonatal medulloblastoma. Brain Dev 2012;34:881-5.

9. Booth TN, Rollins NK. MR imaging of the spine in epidermal nevus syndrome. AJNR Am J Neuroradiol 2002;23:1607-10.

10. Happle R. Epidermal nevus syndromes. Semin Dermatol 1995;14:111-21.

11. Groesser L, Herschberger E, Ruetten A, Ruivenkamp C, Lopriore E, Zutt M, Langmann T, Singer S, Klingseisen L, Schneider-Brachet W, Toll A, Real F, Landthaler M, Hafner C. Postzygotic HRAS and KRAS mutations cause nevus sebaceous and Schimmelpenning syndrome. Nat Genet 2012;44:783-7.

12. Bourdeaut F, Hérault A, Gentien D, Pierron G, Ballet S, Reynaud S, Paris R, Schleiermacher G, Baumann C, Philippe-Chomette P, Gauthier-Villars M, Peuchmaur, M, Radvaniy F, Delattre O. Mosaicism for oncogenic G12D KRAS mutation associated with epidermal nevus, polycystic kidneys and rhabdomyosarcoma. J Med Genet 2010;47:859-62.

13. Vidaurri-de la Cruz H, Tamayo-Sánchez L, DuránMcKinster C, de la Luz Orozco-Covarrubias M, RuizMaldonado R. Epidermal nevus syndromes: clinical findings in 35 patients. Pediatr Dermatol 2004;21:432-9.

14. Asch S, Sugarman JL. Epidermal nevus syndromes: New insights into whorls and swirls. Pediatr Dermatol 2018;35:21-9.

15. Molho-Pessach V, Schaffer JV. Blaschko lines and other patterns of cutaneous mosaicism. Clin Dermatol 2011;29:205-25.

16. Happle R. Lethal genes surviving by mosaicism: a possible explanation for sporadic birth defects involving the skin. J Am Acad Dermatol 1987;16:899-906.

17. Boppudi S, Bögershausen N, Hove HB, Percin EF, Aslan D, Dvorsky R, Kayhan G, Li Y, Cursiefen C, Tantcheva-Poor I, Toft PB, Bartsch O, Lissewski C, Wieland I, Jakubiczka S, Wollnik B, Ahmadian MR, Heindl LM, Zenker M. Specific mosaic KRAS mutations affecting codon 146 cause oculoectodermal syndrome and encephalocraniocutaneous lipomatosis. Clin Genet 2016;90:334-42.

18. Peacock JD, Dykema KJ, Toriello HV, Mooney MR, Scholten DJ 2nd, Winn ME, Borgman A, Duesbery N, Hiemenga JA, Liu C, Campbell S, Nickoloff BP, Williams BO, Steensma M. Oculoectodermal syndrome is a mosaic RASopathy associated with KRAS alterations. Am J Med Genet A 2015;167:1429-35.

19. Munro CS, Wilkie AO. Epidermal mosaicism producing localised acne: somatic mutation in FGFR2. Lancet 1998;352:704-5.

20. Baker RS, Ross PA, Baumann RJ. Neurologic complications of the epidermal nevus syndrome. Arch Neurol 1987;44:227-32.

21. Happle R. The group of epidermal nevus syndromes Part I. Well defined phenotypes. J Am Acad Dermatol 2010;63:1-22; quiz 23-4.

22. Happle R. The group of epidermal nevus syndromes Part II. Less well defined phenotypes. J Am Acad Dermatol 2010;63:25-30; quiz 31-2.

23. Dodge NN, Dobyns WB. Agenesis of the corpus callosum and Dandy-Walker malformation associated with hemimegalencephaly in the sebaceous nevus syndrome. Am J Med Genet 1995;56:147-50.

24. Canyigit M, Oguz KK. Epidermal nevus syndrome with internal carotid artery occlusion and intracranial and orbital lipomas. AJNR Am J Neuroradiol 2006;27:1559-61.

25. Menascu S, Donner EJ. Linear nevus sebaceous syndrome: case reports and review of the literature. Pediatr Neurol 2008;38:207-10.

26. Pavlidis E, Cantalupo G, Boria S, Cossu G, Pisani F. Hemimegalencephalic variant of epidermal nevus syndrome: case report and literature review. Eur J Paediatr Neurol 2012;16:332-42.

27. Ullah W, Abdullah HMA, Shahzad MA, Sadiq MA, Ahmad E, Khan S. First Reported Case of "Epidermal Nevus Syndrome" with a Triad of Central Nervous System Deformities. Cureus 2016;8:e916.

28. Pavone L, Curatolo P, Rizzo R, Micali G, Incorpora G, Garg BP, Dunn DW, Dobyns WB. Epidermal nevus syndrome: a neurologic variant with hemimegalencephaly, gyral malformation, mental retardation, seizures, and facial hemihypertrophy. Neurology 1991;41:266-71. 
29. Juan YH, Nagpal P, Saboo SS, Lin -C, Khandelwal A. Vascular manifestations and post-treatment changes of epidermal nevus syndrome. QJM 2015;108:135-7.

30. Parazzini C, Triulzi F, Russo G, Mastrangelo M,

Cite this article as: De Vito A, Taranath A, Dahmoush H, Ganapathy SS, Sudhakar S, Mankad K. Neuroimaging manifestations of epidermal nevus syndrome. Quant Imaging Med Surg 2021;11(1):415-422. doi: 10.21037/qims-20-634
Scotti G. Encephalocraniocutaneous lipomatosis: complete neuroradiologic evaluation and follow-up of two cases. AJNR Am J Neuroradiol 1999;20:173-6. 